\title{
ASSÉDIO MORAL NA RELAÇÃO DE EMPREGO NO BRASIL DO SÉCULO XXI: POR UM RESGATE DA DIGNIDADE DA PESSOA HUMANA
}

\section{Prof. Mestre Dirceu Pertuzatti}

Formado em Direito pela PUC-PR. Mestre em Ciências Jurídicas pela UNIVALI - SC. Docente e Pesquisador da Faculdade Pitágoras de Curitiba. Membro do Grupo de Estudos e Pesquisas Pitágoras - CEPEP, na área de Políticas Públicas e Direitos Humanos. Redator-Chefe e Membro do Conselho Editorial da Revista Virtual Pitágoras.

Faculdade Pitágoras

e-mail: dirceupertuzatti@uol.com.br

\section{Prof $^{a}$ Dr $^{a}$ Maria de Lourdes Pinto de Almeida}

Pedagoga e historiadora formada pela UNICAMP. Mestre e Doutora em Filosofia, História e Educação pela FE da UNICAMP. Pós-Doc em Políticas Públicas e Direitos Humanos pela USP. Pós-Doutoranda em Ciência Política pela Universidade de Salamanca - Espanha. Docente Pesquisadora da USP e Coordenadora Executiva do Centro de Estudos e Pesquisas Pitágoras, na área de Políticas Públicas e Direitos Humanos. Autora de vários livros publicados pela Editora Átomo e Alínea. www.atomoealinea.com.br.

USP - PITÁGORAS

e-mail: malupalmeida@uol.com.br

RESUMO: O presente texto tem como objetos de estudo o Assédio Moral na Relação de Emprego no Brasil do século XXI e o resgate da dignidade da pessoa humana inserida neste mundo mercadológico capitalista do trabalho, coordenado por um Estado liberal que prega o mínimo para o social e o "Máximo para a acumulação da moeda", em que a aparência é valorizada em detrimento da essência humana, os fins sempre justificando os meios, independentemente do conceito que se tem de Justiça Social. Apresenta como referente comunicativo a proposta de aprofundar os conhecimentos científicos alusivos ao Assédio Moral em colisão com a dignidade da pessoa humana. O tema, em face da reiteração de situações, envolve empregados que são vítimas de Assédio Moral nas suas Relações de Emprego, procurando demonstrar alternativas para coibir a reincidência desses atos, que, pela sua aparente superficialidade, escondem os verdadeiros danos psicológicos e morais causados às pessoas. O estudo visa apresentar certas facetas que envolvem o Assédio Moral e suas repercussões no âmbito da Dignidade do Trabalhador Brasileiro, como estímulo à reflexão tendente a elucidar as condutas assediosas no Ambiente de Trabalho.

PALAVRAS-CHAVE: Assédio moral; Dignidade humana; Transformações no mundo do trabalho. 


\section{INTRODUÇÃO}

A análise do fenômeno Assédio Moral requer uma abordagem para identificá-lo, compreendê-lo e procurar alternativas que coibam a sua reincidência, porque, como será demonstrado, ele causa danos à Pessoa Humana, nos aspectos psíquicos e físicos, e deve ser combatido. Sobre o Assédio Moral, apesar de ter sido identificado recentemente - as primeiras preocupações surgiram na década de 1990, do século passado, em que uma Psicóloga Francesa, Marie-France Hirigoyen (HIRIGOYEN, 2002) pesquisou a incidência desse mal que aflige as pessoas -, tem sido constatado que sua existência remonta a fase da organização do trabalho. A abordagem pretendida, inicialmente, foi a relação de emprego, porém descobriu-se que a manifestação desse fenômeno não era restrita ao ambiente de trabalho, mas também aos domicílios, às corporações, às escolas. Ou seja, não era algo isolado e recente, mas sim algo que, ao longo da história, veio acompanhando a evolução humana em Sociedade. A manifestação do Assédio Moral gera um desrespeito ao Princípio da Dignidade da Pessoa Humana, e, por conseguinte, ao empregado, porque atinge a essência daquele que pretende ter a sua dignidade considerada como forma de justificação da existência humana.

Ao ser abordado o Princípio da Dignidade da Pessoa Humana, como advertência, deve-se entender a questão da dignidade. O conceito de dignidade foi elaborado no decorrer da evolução da humanidade. Inicialmente, era algo considerado de pouca importância, mas, aos poucos, a Pessoa Humana chegou ao entendimento de que a sua valoração era muito importante. Ou seja, ao dar a devida importância à dignidade, estaria também protegendo a sua verdadeira identidade.

Nunes (2002, p.49), ao definir dignidade, entende que a Pessoa Humana é digna porque é, trazendo consigo, a Dignidade, ou seja, referindo-se à sua essência porque é preciso levar em conta todas as violações que foram praticadas, procurando repudiá-las.

A categoria dignidade pode ser entendida, na visão de Abbagnano (2003, p.276-277), como sendo "uma pedra de toque para a aceitação dos ideais ou das formas de vida instauradas ou propostas". E é sobre essa aceitação que se deve seguir com a busca do conhecimento da essência humana. É algo imprescindível a todo aquele que tem vontade de viver. Para chegar a esta constatação, não é 
conveniente que apenas o indivíduo seja observado, mas também a sociedade que o abriga, de forma coerente ou não.

Não basta a análise da Pessoa Humana sem ter como parâmetro a questão do dever social em que a sociedade deve tratar a Pessoa Humana com dignidade. Esse tratamento não se restringe unicamente às questões do pensamento, mas também às de moradia, à condições de trabalho, saúde, educação, entre outros ramos necessários à sobrevivência. Ou seja, sabe-se que a dignidade é onipresente no viver humano. Especificamente para esta pesquisa será analisada a dignidade na relação de emprego, bem como sua ausência e os aspectos jurídicos que dela originam, como, por exemplo, o surgimento do Assédio Moral.

É importante destacar agora, para compreender a dignidade, a forma de utilização do Princípio da Proporcionalidade na busca por uma isonomia no aspecto humano. Por mais que se saiba da igualdade e seu aspecto fundamental na sociedade, tem-se a consciência de que cada Pessoa Humana é diferente e tem a sua essência com determinadas peculiaridades atribuídas a cada um.

Ocorre, porém, que, apesar do deságio de encontrar a igualdade perante todas as desigualdades, se procura o equilíbrio nas relações sociais. Sabe-se das diferenças em termo da essência de cada ser e de suas peculiaridades. E é esse objetivo que o operador do Direito deve ter presente em todas suas atitudes, gerando, com isso, um fortalecimento do Direito como um instrumento de proteção à pessoa.

O Princípio da Proporcionalidade busca a harmonia, articulando os demais princípios (NUNES, Rizzatto, 2002, p. 54). Destaca-se deste princípio o fato de que sua utilização torna mais clara a compreensão da Pessoa Humana e mais próxima da verdade. Isto porque, na proporção que cabe a cada Pessoa Humana, deve ser levada em consideração, sob pena de incidir em erros do passado em que todos eram considerados iguais, desprezando determinados Valores e suprimindo a verdadeira expressão dos direitos humanos.

$\mathrm{Na}$ solução de muitos conflitos, como, por exemplo, da intimidade, da vida privada, da honra, da imagem da pessoa, entre outros, utiliza-se o respeito à dignidade, por meio da utilização do Princípio da Proporcionalidade para se chegar a uma solução mais justa. E o resultado seria a obtenção da isonomia, mas o bem a 
ser protegido será, sem dúvida, a dignidade da Pessoa Humana como um princípio absoluto (NUNES, Rizzatto, 2002, p.57).

Portanto, o princípio da dignidade da Pessoa Humana tem seu conceito atual como a valoração jurídica dos valores humanos, cada qual em suas devidas proporções, tendo sempre como fonte a essência humana. Esse conceito não é imutável. Isso porque não apenas a Pessoa Humana tem evolução, mas também a sociedade e todos os outros segmentos necessários à sobrevivência. A forma que será dada a esta evolução influenciará diretamente a atualização do conceito. $E$ isso deve ocorrer como uma necessidade de um dinamismo no tratamento da Pessoa Humana.

A partir desta orientação feita em relação aos princípios, regras, valores, direitos de personalidade e ao princípio da dignidade da Pessoa Humana, sempre destacando a proteção aos direitos de toda Pessoa Humana, busca-se o estudo das relações humanas e sociais, que serão abordadas na seqüência desta pesquisa. Destaca-se, porém, que a inobservância deste princípio ora mencionado gera, como conseqüência, um desequilíbrio na relação de emprego, que, por sua vez, causa o Assédio Moral.

Muitos pesquisadores da área, (FERREIRA, Hádassa D. B., 2004) analisam o fenômeno do Assédio Moral sob o ponto de vista da relação de trabalho. Ocorre que essa relação envolve, além da relação de emprego, qualquer relação, não apenas no trabalho, mas também nos domicílios, nas escolas, nas corporações, enfim, em diversos lugares que tornariam o estudo abrangente e sem uma perspectiva de objetividade científica. A relação de trabalho é gênero, enquanto a relação de emprego é espécie, e se firma nos preceitos que descrevem essa relação nos cinco elementos fundamentais: a) pessoalidade (intuito personae); b) subordinação; c) não eventualidade; d) onerosidade; e) Pessoa Natural. Por essa razão, será analisado especificamente o Assédio Moral na relação de emprego.

O fenômeno do Assédio Moral na Relação de Emprego tem uma incidência específica na convivência entre empregado e empregador, em que se registra a ocorrência de um superior hierárquico sobre um subordinado, entre colegas de trabalho e até mesmo, apesar de ser minoria, do subordinado contra o superior hierárquico. 
Antes, porém, em razão do conteúdo do fenômeno Assédio Moral, deve-se perquirir as questões que envolvem a moral e a ética nas relações de emprego, bem como o fato de que a inobservância desses preceitos geraria conseqüências danosas ao trabalhador. Para se ter uma noção da amplitude desses danos, será abordado, especificamente, o Assédio Moral, fornecendo-se subsídios para a compreensão desse fenômeno, com causas e efeitos à Pessoa Humana e, por conseguinte, à sua dignidade. Portanto, a partir deste momento, buscam-se as razões que o Direito pode fornecer à Pessoa Humana que procura uma solução jurídica às mazelas causadas na relação de emprego. Não há, portanto, a pretensão de esgotar todos os pontos em relação ao fenômeno aqui discutido, pois, como se sabe, a Pessoa Humana ainda está em busca da solução para suas dificuldades, e a ciência não se esgota em si. Sempre haverá novas versões e perspectivas de análise sobre essa temática tão atual, contundente e polêmica. Pretende-se, assim, com fundamento em determinadas doutrinas que serão fornecidas no desenvolvimento desta pesquisa, desenvolver uma intenção de construir e desvendar um questionamento sobre as relações humanas no ambiente de trabalho, tendo como conseqüências as atividades laborais, bem como o engendramento da práxis jurídica no que diz respeito ao Assédio Moral.

\section{DIREITO, MORAL E ÉTICA: UMA BREVE DISCUSSÃO}

Para que se possa ter uma concepção do atual contexto histórico e jurídico que envolve o Assédio Moral, deve-se perquirir a respeito do conceito de Direito. Como proposta, obtém-se acesso ao estudo elaborado por Radbruch (2004, p.47) quando trata sobre Direito e Moral. Esse autor comenta que o conceito de Direito é um conceito cultural, de uma situação em que há referência a valores, cujo sentido é o de estar a serviço destes. Conclui, em seguida, que "o Direito é a realidade que tem o sentido de servir ao valor jurídico, à idéia do Direito" (SILVA, M. M. 2003, p.117-118). Esse pensamento será adotado para fins de fundamentação dos argumentos apresentados. Feitas essas considerações, passa-se, agora, ao conceito de moral.

Já em relação ao estudo sobre a moral, tem-se o seu significado como sendo "atinente à conduta e, portanto, suscetível de avaliação Moral, especialmente de 
avaliação Moral positiva". Nesse conceito, Abbagnano (2000, p.682) comenta, ainda, que não há o que se falar apenas de atitude Moral para mencionar um ato moralmente valorável, mas também de coisas positivamente valoráveis e, portanto, boas. A moral, ao ser definida, não pode ser entendida como sinônimo de ética, como bem mencionou Melo (2000, p.65). Radbruch (2004, p.57), ao trabalhar o conceito de moral, comenta sobre as "boas intenções das quais o inferno está cheio".

Radbruch (2004, p.66) aborda com propriedade, ao tratar da moral, que "só a Moral pode fundamentar a força obrigatória do direito. [...] Pode-se falar somente de normas jurídicas, de dever ser jurídico, de validade jurídica e de deveres jurídicos quando o imperativo jurídico for abastecido pela própria consciência com a força de obrigação moral". Essas considerações são importantes ao tratar a questão do Assédio Moral, justificando e definindo as partes que agem, sob impulso, prejudicando seu semelhante, sob a égide de um cargo ou função, alegando uma "boa intenção".

\section{MORALIDADE SUBJETIVA E MORALIDADE OBJETIVA}

Hegel, ao tratar da moralidade subjetiva, argumenta que a moral não se define como oposto do que é imoral, bem como de que o Direito também não se define como o contrário do injusto. Ou seja, tanto o domínio da moral como o do imoral baseiam-se na subjetividade da vontade; que é abstrata, limitada e formal (HEGEL, G. W. F. 1997, p.98-99). Ou seja, em uma lição, Silva (2003, p.120-121), ao analisar a obra de Hegel, entende que, para se obter uma compreensão da moralidade subjetiva, deve-se ter em pensamento de que há uma estreita ligação com a vontade subjetiva particular do ser, buscando referência na vontade universal. A vontade, segundo esse raciocínio, é influenciada pelo princípio da razão, pois a vontade interior do ser constitui o sujeito. E a moral subjetiva tem em seu contexto a idéia que é preciso reconhecer no seu semelhante aquilo que deseja para si. Apesar de haver uma busca do bem, encontra-se implicitamente a idéia do mal, sendo distintos apenas pela vontade. Ao exprimir essa vontade, o ser precisa estar no gozo da liberdade para optar pelo bem em relação ao mal.

Somente quando a vontade moral subjetiva se exterioriza pode-se afirmar que há uma ação (HEGEL, 1997, p.102). E conclui Hegel (1997, p.102-103), a respeito do 
direito da vontade moral subjetiva, destacando três aspectos: a) o direito abstrato ou formal da ação deve ser manifestado pela vontade subjetiva de cada ser; b) refere-se ao conteúdo interior, o particular da ação, em que o caráter universal é determinado para o ser, como aquilo que validade para si mesmo; c) o conteúdo assume sua universalidade, a sua objetividade é o fim absoluto da vontade, e o bem que é acompanhado ao se fazer a reflexão, opondo-se à universalidade, objetiva, em parte, da forma de mal, e em outra, na forma de certeza moral.

Parte-se agora, para a análise da moralidade objetiva. Para Hegel, a moralidade objetiva "é a idéia da liberdade enquanto vivente bem, que na consciência de si tem o seu saber e o seu querer e que, pela ação desta consciência, tem a sua realidade" (1997, p.141). A moralidade objetiva consiste no fato de que a pessoa tem a necessidade de, subjetivamente, estar designada à liberdade para a sua satisfação (1997, p.198). E essa objetividade consistia na verdade da certeza da sua Liberdade, bem como na verdade moral, apresentando em sua última universalidade uma essência própria (HEGEL, 1997, 148).

$\mathrm{Na}$ identidade da vontade universal e da particular, há que se perquirir a questão do dever e do direito, pois no mundo moral objetivo a Pessoa Humana têm deveres na medida em que têm direitos na proporção de seus deveres (HEGEL, 1997, p.148). Hegel afirma que, portanto, na moralidade subjetiva o Direito da consciência que o ser apresenta e sua vontade e felicidade igualam-se ao dever e apenas como dever-ser são objetivos. $\mathrm{Na}$ elaboração dos estudos sobre a moralidade objetiva, Hegel entabula os aspectos referentes à família (1997, p.216), à sociedade civil (1997, p.167) e ao Estado (1997, p.216).

Em outras palavras, Silva (2003, p.121) comenta que moralidade objetiva tem em seu conteúdo, observando o ponto de vista da Filosofia do Direito de Hegel, o qual designa de eticidade, cujo conceito está na idéia de liberdade. E o ser desprende-se de si para incorporar-se ao meio social. Em relação à vontade, que é própria do ser, a qual o inspira, baseia-se na razão. Para os objetivos desta pesquisa, haverá a concentração nas definições apresentadas, como fundamentos aos argumentos sobre o Assédio Moral, os quais justificarão a razão da Pessoa Humana quando se relaciona com seu semelhante, no contexto do trabalho.

Ao comentar sobre a ética, sabe-se que essa palavra é oriunda da língua grega na palavra êthîcê, ês, Ethika, que, na visão de Silva (2003, p.114), ao citar 
Kant, estabelece como "em sentido amplo, a ciência que investiga a conduta livre, consciente, responsável do Ser Humano". Essa definição adota-se para fins desta pesquisa, em razão do referente Assédio Moral.

Portanto, não será tratada questão conceitual em que se estabeleçam as diferenças entre moral e ética. A proposta feita é no sentido de adotar-se um conceito para Ética e inseri-la no contexto das Relações de Emprego.

Ao trabalhar o Assédio Moral, procura-se saber as razões de seu surgimento. Para a lógica do presente estudo, a abordagem torna-se necessária, sob um ponto de vista psicológico. Leva-se em conta, acima de tudo, a personalidade dos indivíduos e sua história, bem como o aspecto organizacional que define essencialmente as regras de gestão (HIRIGOYEN, 2002, p.185).

Por uma razão investigativa, deve-se ter em pensamento que o estudo do Assédio Moral na relação de emprego não é um fato isolado, ou seja, não é visualizando apenas o empregado que se obterá um esclarecimento dos fatos, nem também de forma contextualizada o ambiente de trabalho, as relações profissionais, enfim, todos os fatores que direta ou indiretamente influenciam, com maior ou menor intensidade, o surgimento do Assédio Moral na relação de emprego.

No entendimento de Hirigoyen (2002, p.187), não há um perfil psicológico padrão para as vítimas, mas sim contextos profissionais em que os procedimentos de Assédio Moral tornam-se propícios à sua manifestação. Somente com a análise detalhada das condições em que o Assédio surge é possibilitada a sua compreensão. Eventualmente, o assédio é confundido com o estresse profissional, que é comum na relação de emprego. Embora o estresse cause um desgaste psíquico e sofrimento, não constitui em si uma forma de assédio, apesar dessa situação ser um prenúncio de uma ocorrência agravada (HIRIGOYEN, 2002, p.188). O que faz a diferença nessa constatação é a forma que ocorre, a intensidade, bem como os requintes ardis que são peculiares do Assédio Moral.

No ambiente de trabalho, há a contribuição significativa para o agravamento do equilíbrio na relação de emprego. Sabe-se que, atualmente, as organizações empresariais têm uma meta em que os ritmos de trabalho são fixados, as interrupções restringidas, a comunicação é limitada ao mínimo estrito, tudo sobre a pressão implacável do relógio (HIRIGOYEN, 2002, p.188-189), bem como o pedido da determinação em obter, em menor tempo possível, a melhor qualidade 
adequada, na maior produtividade permitida. $\mathrm{O}$ problema surge quando não há o limite do respeito às condições mínimas de dignidade humana do trabalhador, ou seja, há uma preocupação com a valoração da força de trabalho. Ocorre que, atualmente, essa valoração não é no sentido de resgatar aquilo que foi ignorado com modernização do trabalho, mas sim em uma preocupação constante que, diante de uma grande oferta de mão-de-obra, é dada a preferência ao empregado que melhor possa desempenhar suas funções, transformando-o em lucro. $O$ aspecto humano que deveria ser enaltecido na relação de emprego permanece em segundo plano, gerando a quebra da harmonia nessa relação. Na ilustração de Hirigoyen (2002, p.189), "quando um [empregado] assalariado se desmotiva, ninguém lhe pergunta sobre as razões de seu desânimo, mas é rejeitado por não conformidade, por não ser suficientemente combativo".

Neste início de século XXI, nas empresas, procuram-se administrar aos empregados cursos que proporcionem a convivência com o estresse profissional. Algumas técnicas empregadas nesses cursos têm sido utilizadas para selecionar melhor o empregado. Essa sistematização gera um processo de robotização das pessoas (HIRIGOYEN, 2002, p.190), que agem de forma tensa no seu dia-a-dia, gerando problemas no ambiente de trabalho.

O seguinte fator a ser estudado consiste no caso da padronização nas empresas, em que os valores individuais são escamoteados, em razão de que se entende que ao ingressar em uma empresa está implícita a idéia de aceitar seus valores, suas normas e sua maneira de pensar (HIRIGOYEN, 2002, p.196). Nesse estudo, percebe-se que a forma de padronizar age de maneira agressiva, não permitindo que o empregado possa manifestar sua opinião.

A falta de reconhecimento tem sido também atribuída como uma origem do Assédio Moral. Isso porque o trabalho desempenha um papel fundamental à dignidade do empregado, que somente se encontra em sua plenitude quando este tem o seu valor na sociedade reconhecido pelo seu trabalho. Nesse sentido, a inexistência do reconhecimento ensejaria um sentimento de desmotivação, causando, assim, um estado de depressão em que o trabalhador não tem mais vontade de se dedicar emocionalmente ao trabalho. No entendimento de Hirigoyen (2002, p.198-199) sobre a falta de reconhecimento, este é evidenciado quando o 
"desprezo pelo outro é o primeiro passo na direção do assédio moral e da violência. É uma tática inconsciente para manter o domínio e desqualificar as pessoas".

No estudo das formas de organização, estão compreendidas as empresas privadas, órgãos públicos etc., sabe-se que há a manifestação de patologias individuais e coletivas atribuídas a esses ambientes. As organizações não se preocupam em proteger seus empregados e acabam permitindo, em razão dessa indiferença, o ambiente propício ao Assédio Moral (HIRIGOYEN, 2002, p.203). O que se pretende com essa afirmação é demonstrar que a forma de agir dessa organização gera um sistema vicioso em que a agressão se torna implícita, ou seja, em uma determinada tomada de decisão, em que são estimuladas as disputas pela competitividade acirrada, em troca de pequenas compensações no final de cada mês, faz-se com que alguns funcionários se calem, aceitando as regras, sem reclamar. Nesse sentido, as questões que envolvem os empregados geralmente são desprezadas, e todo o clima de agitação de uma organização acaba sufocando a voz daqueles que estão sendo vítimas do Assédio Moral na relação de emprego.

Com essa perspectiva, não se pretende combater todo e qualquer tipo de atividade que envolva o aspecto motivacional de uma organização. Pretende-se, sim, fazer com que a dignidade do trabalhador seja respeitada, ou seja, que toda pessoa possa manifestar seus pensamentos, contribir para a melhoria de uma empresa, sem que ela seja vista apenas como um número de matrícula funcional que conste do registro dos empregados, mas sim alguém que contribui para a organização, em que, apesar do aspecto coletivo, o indivíduo seja valorizado por aquilo que ele é em sua essência.

Deve-se, nesse contexto, destacar determinadas situações que surgem em determinados ambientes de trabalho, como a fuga à responsabilidade, em que os próprios colegas de repartição esforçam-se para encontrar alguém culpado diante de um problema ocasionado por uma falha humana. É dessa forma que dirigentes responsáveis por fracassos nem sempre assumem suas conseqüências. É desse modo que aqueles que assediam colegas ou subordinados possuem a intenção de acusar os outros ou o sistema organizacional (HIRIGOYEN, 2002, p.205).

O problema gerado pela falta de harmonia na relação laboral também pode ser justificado pela megalomania (LALANDE, 1999, p.659) dos dirigentes que não medem conseqüências para a obtenção de seus resultados preestabelecidos 
(HIRIGOYEN, 2002, p.205-206). Para justificar uma atitude agressiva, fundamentam que o mercado atual é altamente competitivo em que fica estabelecida a luta de "vida ou morte" entre os concorrentes. Com isso fica claro que há uma "guerra" em que todos competem com todos, demonstrando um verdadeiro caos frente à sociedade a que se entende como sendo organizada.

As situações aqui apresentadas demonstram que ao ser constatado o perfil das empresas que foi alterado significativamente em razão do contexto social. O que fica evidenciado é o fato de a sociedade ter adquirido uma postura narcisista (LALANDE, 1999, p.1281), em que o egoísmo é cultuado. A sociedade é fundada na imagem, ou seja, o que importa é a aparência, e os valores humanos são colocados em segundo plano. Ou seja, hoje não basta ser um cientista honesto ou um alto executivo sério, é preciso anunciar-se e fazer a própria divulgação. Nesse contexto, a sociedade adquire característica de superficialidade, em que o que importa é o acúmulo de reservas financeiras, o sucesso e um bom currículo para alcançar os melhores empregos, não importando os meios utilizados para atingi-los (HIRIGOYEN, 2002, p.213-214).

Os pontos aqui mencionados contribuem para uma análise mais apurada do contexto em que se manifesta o Assédio Moral. Ao descrever a sociedade e seus percalços, verifica-se que suas influências são sentidas diretamente na relação de emprego. Havendo essa quebra de harmonia, cria-se a ocasião propícia à agressividade e, por conseguinte, à perversão, característica fundamental do Assédio Moral.

Destaca-se, antes de abordar o conceito de Assédio Moral, por uma justificativa plausível, a de demonstrar os aspectos econômicos que propiciam situações em que surge o Assédio Moral. Esse fenômeno surgiu ainda no início da sociedade de trabalho organizada (FERREIRA, 2004, p.37). Porém, somente agora houve o alerta para os danos que são causados em decorrência desse fenômeno. Sabe-se, também, que o Assédio Moral não é de exclusividade do Direito do Trabalho, mas sim de todos os segmentos da sociedade - sendo possível a sua manifestação até mesmo nos lares, escolas, ou seja, no cotidiano que envolve a Pessoa Humana. Especificamente para esta pesquisa, é abordado o Assédio Moral no trabalho. $E$ isso pode ser constatado ao analisar o ambiente do trabalho, em que o trabalhador passa boa parte de seu tempo submetendo-se a pressões, muitas 
vezes desmedidas, impulsionadas por uma competição laboral e que acaba se transformando em insegurança e, ao mesmo tempo, no medo da demissão (FERREIRA, 2004, p.37). Esse processo em que o trabalhador é submetido às pressões tem reflexo direto na sua higidez física e psíquica.

Registra-se aqui o pioneirismo da psiquiatra francesa Marie-France Hirigoyen (2002) ao lançar dois livros: Assédio Moral - $A$ violência perversa no cotidiano - cuja 1a edição é de 1998, e o Mal-Estar no Trabalho - cuja edição é de 2001. Obras estas que servirão de referência para definir o Assédio Moral, nas quais se percebe a abordagem feita em linguagem própria da psiquiatria, psicanálise, bem como da medicina do trabalho, buscando fundamentação em estudos de casos.

\section{CONSIDERAÇÕES FINAIS}

Com o objetivo de buscar o conceito operacional para Assédio Moral, ressalta-se a abrangência que esse fenômeno desperta nas pessoas. O grau de incidência deve ser medido de acordo as conseqüências que a manifestação desse evento causou. O Assédio Moral não é exclusivo da relação de trabalho. É nesse ambiente que há a manifestação mais expressiva do Assédio Moral, pelos seguintes motivos: a fiscalização exercida pelos sindicatos organizados que o denunciam ao Poder Judiciário, que está ligado ao Direito do Trabalho, bem como pelos representantes dos empregadores que, preocupados com as conseqüências incidentes nos trabalhadores em que geram prejuízo, resolvem dar-lhes mais atenção, fazendo com que esta ocorrência seja controlada, com vistas a atingir a sua eliminação.

O Assédio Moral manifesta-se mediante atos perversos e corriqueiros em lugares como a escola, locais de lazer, nos domicílios, bem como no ambiente de trabalho. Esses atos partem de uma simples falta de respeito, mentira ou até mesmo uma manipulação (HIRIGOYEN, Assédio Moral, 2002, p.19). Especificamente, para esta pesquisa, os estudos são considerados sobre os aspectos jurídicos do Assédio Moral no ambiente de trabalho.

Hirigoyen (Assédio Moral, 2002, p.65) define assédio em um local de trabalho como sendo "toda e qualquer conduta abusiva manifestando-se, sobretudo, por comportamentos, palavras, atos, gestos, escritos que possam trazer danos à 
personalidade, à dignidade ou à integridade física ou psíquica de uma pessoa, pôr em perigo seu emprego ou degradar o ambiente de trabalho". Ou seja, pode ser constatado que a conceituação do Assédio no local de trabalho não é uma simples e objetiva definição, mas sim uma constatação complexa de atos que, somados, geram o assédio.

O assédio no ambiente de trabalho tem sua origem vinculada à existência do trabalho. Porém, somente a partir do início da última década do século $X X$ houve uma preocupação de seus efeitos. Os primeiros estudos a respeito desse assunto foram feitos nos países anglo-saxões e nos países nórdicos, classificando-o como mobbing, cujo termo é derivado da palavra mob, que significa horda, bando ou plebe, implicitamente contemplando a idéia de algo inoportuno (HIRIGOYEN, 2002, p.66). Hirigoyen destaca a pesquisa desenvolvida pelo pesquisador em Psicologia do Trabalho, Heinz Leymann (HIRIGOYEN, 2002, p.66-67), o qual qualifica o assédio como "psicoterror". Essa designação demonstra um estudo conclusivo de uma situação prática em que a pressão sofrida no ambiente de trabalho torna-se insuportável à Pessoa Humana, que sucumbe diante das investidas do agressor, anulando-se psiquicamente com alguns reflexos em sua integridade física.

Todo grupo manifesta os conflitos entre seus membros. Determinados comentários ou brincadeiras inconvenientes feitos no local de trabalho, humilhação, ou até mesmo situações vexatórias a que o trabalhador é exposto geram problemas no convívio diário. Nesse contexto, surge o assédio como que algo inofensivo em seu princípio, porém, que se propaga insidiosamente (HIRIGOYEN, 2002, p.66).

Assediar tem a conotação de perseguição ou insistência, ou seja, de importunar até que alguém, a vítima do assédio, aceite as insinuações do autor da ação. Não importam as conseqüências para o assediador, desde que ele consiga os resultados pretendidos. A vítima do assédio nem sempre pode resistir às investidas do agressor, que, utilizando-se de meios ardilosos, oprime, de forma abusiva, com conseqüências danosas ao trabalhador e, por conseguinte, à empresa.

Ao agregar à expressão "assédio", a palavra "moral", na justificativa de Hirigoyen (2002, p.15), seria a de que haveria uma qualificação psicológica, fundamentada em estudos sobre os mecanismos psicológicos utilizados quando da manifestação desse fenômeno. Entende a autora que esta decisão da adoção do termo "moral" implicaria numa tomada de posição em que "trata-se efetivamente de 
bem e de mal, do que se faz e do que não se faz, e do que é considerado aceitável ou não em nossa sociedade" (HIRIGOYEN, 2002, p.15). Razão pela qual optou-se por adotar um conceito de moral e ética para condução desta pesquisa. Isso é justificável em razão do fato de que a incidência do Assédio Moral gera o desrespeito à dignidade humana, e, por conseguinte, o abalo às questões morais e éticas atribuídas ao trabalhador. E se não houver uma providência imediata contra a crescente incidência do Assédio Moral, haverá prejuízo aos princípios que têm como objetivo a Proteção ao Trabalho.

Portanto, toma-se como referência o conceito proposto por Hirigoyen (2002, p.17), de que o Assédio Moral no trabalho "é definido como qualquer conduta abusiva que atente, por sua repetição ou sistematização, contra a dignidade ou integridade psíquica ou física de uma pessoa, ameaçando seu emprego ou degradando o clima de trabalho". Ao referir-se à expressão "conduta abusiva", a autora classifica como qualquer gesto, palavra ou comportamento que venha a agredir a pessoa no ambiente de trabalho. Percebe-se claramente que a definição de Assédio Moral não significa apenas um ato isolado, mas também uma seqüência de investidas por parte do assediador sobre a vítima. São atos, sob a visão de um observador externo, cuja conduta, pelo fato de ser isolada, não comprometeria a dignidade do trabalhador. Ocorre que, por uma constatação evidente, a somatória desses atos isolados constituiria um quadro psicológico em que a convivência no ambiente de trabalho tornaria-se insuportável e traria conseqüências danosas ao trabalho.

A incidência do Assédio Moral na relação de emprego gera a ofensa ao princípio da dignidade da Pessoa Humana, e deve ser motivo de preocupação ao operador do Direito que, ao se deparar com a manifestação desse fenômeno, deverá agir com rigor, extirpando-o da sociedade em razão de sua agressão à dignidade do trabalhador. Ao justificar a questão da moralidade subjetiva, constatou-se que somente quando a vontade moral subjetiva se exterioriza, pode-se afirmar que há uma ação; enquanto, a moralidade objetiva consiste no fato de que a pessoa tem a necessidade de, subjetivamente, estar designada à liberdade para a sua satisfação. E é sobre essa liberdade, bem como a sua restrição, que se faz importante o estudo do Assédio Moral, pois este cerceia, prejudica e fere a dignidade da Pessoa Humana. 
Atualmente, o Assédio Moral manifesta-se nas organizações impulsionadas pelo estado liberal que prega o entendimento de que há o mínimo para o social e o máximo para a acumulação da moeda, em que somente o lucro importa e a valoração humana fica em último plano. Ou seja, não importa como o empregado está, mas sim quanto ele produziu. Não interessa saber àquele que detém o poder diretivo em uma determinada organização se o empregado é representado por uma Pessoa Humana, mas sim apenas uma matrícula, um número que ao final de cada mês proporciona determinada produção. E essa situação é propícia à incidência do Assédio Moral e, por conseguinte, à ofensa ao princípio da dignidade da Pessoa Humana.

Constatadas essas afirmações, urge manifestar o alerta para esse fenômeno que gera problemas ao empregado, quer na ordem psíquica, quer na física. $O$ empregado, trabalhando sobre a influência do Assédio Moral, sente-se desistimulado a produzir de acordo sua capacidade, não é valorizado em sua essência e, por conseqüência, instiga-o a pedir demissão, o que gerará problemas que se manifestarão em cadeia, refletindo diretamente na sociedade organizada. $O$ empregador, que contribui em grande parte para a manifestação do Assédio Moral, não percebe que sua atitude, ao ofender o seu subordinado, acabará atingindo a parte mais sensível de sua organização, a financeira e, indiretamente, a sociedade.

A proposta feita de adotar medidas no sentido de coibir a incidência do Assédio Moral vem corroborar com o resgate da dignidade da Pessoa Humana no Brasil do século XXI, sempre com o pensamento presente de que a busca por uma sociedade mais justa começa com a preocupação ora externada, para justificar e valorizar a existência humana.

\section{REFERÊNCIA DAS FONTES CITADAS:}

ABBAGNAMO, Nicola. Dicionário de Filosofia. Tradução de Alfredo Bosi. 4. ed. São Paulo: Martins Fontes, 2000. 1014 p. Título original: Dizionario di Filozofia.

FERREIRA, Hádassa Dolores Bonilha. Assédio Moral nas Relação de Trabalho. Campinas: Russell Editores, 2004. $156 \mathrm{p}$.

HEGEL, Georg Wilhelm Friedrich. Princípios da Filosofia do Direito. São Paulo: Martins Fontes, 1997. 329 p. Título original: Grundlinien der philosophie der rechts. 
HIRIGOYEN, Marie-France. Assédio Moral: a Violência Perversa no Cotidiano. Tradução de Maria Helena Kühner. 5. ed. Rio de Janeiro: Bertrand Brasil, 2002. 224 p. Título original: Le harcèlement moral.

HIRIGOYEN, Marie-France. Mal-estar no Trabalho. Tradução de Rejane Janowitzer. Rio de Janeiro: Bertrand Brasil, 2002. 352 p. Título original: Malaise dans le travail.

LALANDE, André. Vocabulário Técnico e Crítico da Filosofia. 3. ed. São Paulo: Martins Fontes, 1999. $1336 \mathrm{p}$.

MELO, Osvaldo Ferreira de. Dicionário de Política Jurídica. Florianópolis: OAB/SC, 2000. 104 p.

NUNES, Rizzatto. O Princípio Constitucional da Diginidade da Pessoa Humana. São Paulo: Saraiva, 2002. $127 \mathrm{p}$.

RADBRUCH, Gustav. Filosofia do Direito. Tradução: Marlene Holzhausen. São Paulo: Martins Fonte, 2004. 302 p. Título original: Rechtsphilosophie.

SILVA, Moacyr Motta da. Direito, Justiça, Virtude Moral \& Razão. Curitiba: Juruá Editora, 2003. 200 p. 